IAC-10-C2.2.2

\title{
A SELF-DEPLOYING AND SELF-STABILIZING HELICAL ANTENNA FOR SMALL SATELLITES
}

\author{
J. Block \\ German Aerospace Center (DLR), Germany, joachim.block@dlr.de \\ A. Bäger ${ }^{1}$, J. Behrens ${ }^{2}$, T. Delovski ${ }^{3}$, L.-C. Hauer ${ }^{4}$, M. Schütze $^{5}$, R. Schütze ${ }^{6}$, T. Spröwitz ${ }^{7}$
}

Space antennas with a helical geometry are an advantageous choice for many applications, for instance if the transmission of electromagnetic waves with a circular polarization is intended, or if signals from terrestrial objects shall be received with a high angular resolution. In all these cases the desired electromagnetic properties of a helical geometry can be combined with the mechanical advantage that the antenna acts as a compression spring, provided that its core structure has the necessary high spring stiffness but can nevertheless easily be compressed. Such an antenna has been developed by DLR Institutes in Bremen and Braunschweig together with some industrial partners for a small satellite named AISat which shall be able to pursue the position of individual ships in critical sea areas in order to improve the security of seafare trade. The development was very challenging since the antenna must expand from a stowed stack length of only 10 centimeters to a total length of 4 meters. Only a special carbonfiber core under the conductive coating and a system of stabilizing cords led to a satisfying solution. Both the self-deployment and the self-stabilization function of this innovative antenna concept have been successfully tested and verified under zero-gconditions in the course of a parabolic flight campaign. It could be convincingly demonstrated that the helical antenna can really achieve its desired contour in weightlessness within some seconds and maintain the required stability. Beyond the current application for the AISat satellite it is therefore a quite promising concept for future satellites.

\section{INTRODUCTION}

Helical antennas offer some outstanding properties in comparison with other types of antennas ${ }^{1,2}$ : They are ideally suited for transmitting and receiving circularly polarised electromagnetic waves, and they have an excellent directionality. Their gain increases with the number of windings, at least up to 7 or 8 windings. The higher the achievable gain, the narrower becomes the angle of aperture. On their backside helical antennas need a conductive plate which acts as reflector.

Due to these characteristics helical antennas are an ideal option for space applications where a satellite in orbit shall "illuminate" only a comparatively small footprint area on ground. A paradigmatic example for such a mission is the AISat project which will be explained in the following. The innovative antenna concept which has been developed for this project could be easily transferred also to other small satellites in the future.

${ }^{1}$ DLR (D), annette.baeger@dlr.de

${ }^{2}$ DLR (D), joerg.behrens@dlr.de

${ }^{3}$ DLR (D), toni.delovski@dlr.de

${ }^{4}$ DLR (D), lars-christian.hauer@dlr.de

${ }^{5}$ Schütze (D), martin.schuetze@,schuetze-staebe.de

${ }^{6}$ Schütze (D), rainer.schuetze@schuetze-staebe.de

${ }^{7}$ DLR (D), tom.sproewitz@dlr.de

\subsection{The AISat Project}

AISat is a suitcase-sized nanosatellite with a $4 \mathrm{~m}$ long helical antenna. The 'AIS' in the mission name stands for Automatic Identification System - a radio system designed for the exchange of navigation, position and identification data from each and every vessel, to make global maritime traffic safer and easier to control. The excellent directionality of the helical antenna shall allow to precisely locate individual ships from an orbital position in $\approx 600 \mathrm{~km}$ height, even if the sea route is very busy and the distance between the ships is small, and to receive Search And Rescue (SAR) signals sent from survival craft or distressed vessels.

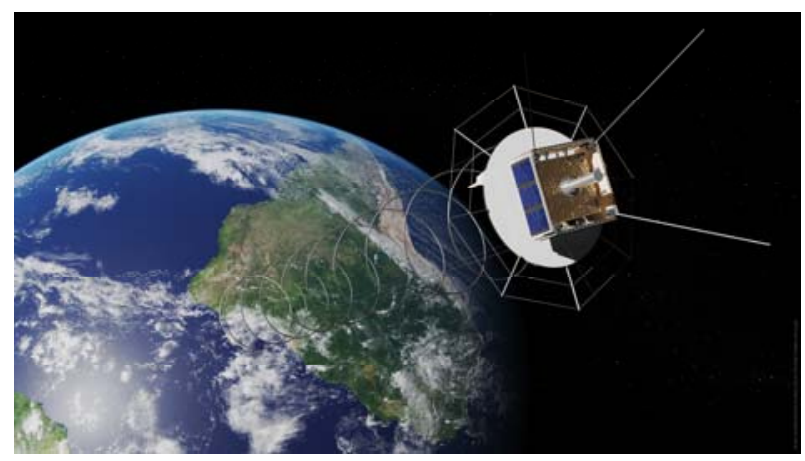

Fig. 1: AISat in space (artist's view) 
Up to now this was not possible: Firstly, satellites usually receive signals from a much larger area, and secondly, many interfering signals are present in adjacent frequency bands.

\subsection{The Antenna Concept}

It is evident that a spaceborne helical antenna must be compressible and stowable in a very small volume during launch, in particular, if the relation between the antenna length $(4 \mathrm{~m})$ and the satellite size is so disproportionate as in this case. Consequently, the helical geometry, which was already predefined by the aforementioned electromagnetic requirements, shall be utilized for a second objective, namely to enable the antenna to act mechanically as a compression spring. Once in orbit, the spring will be released and immediately deploy itself until it has achieved its full operational length. In this final position, thin retracting cords will limit the further expansion against the residual spring force (Fig. 2).

The chronological separation of mechanical and electrical functions suggests a physical separation of the antenna materials as well: While the antenna core needs a high spring stiffness but no electrical conductivity, the properties of the outer skin must be just vice versa: an excellent electrical conductivity, but no mechanical stiffness at all. Therefore it was decided to cover the core with a thin metallic fabric tube consisting of tinned copper wires. The core itself is a cylindrical sandwich strut which obtains its mechanical stiffness from a fiber fabric hose, that surrounds again an inner core made of hard foam. Preferably the fibers are carbonfibers, but glassfibers or aramide fibers could alternatively be selected (depending on the required spring constant).

\subsection{AISat Project Partners and Schedule}

Two institutes of the German Aerospace Center (DLR) are involved in the AISat project: The Institute of Space Systems in Bremen developed the main body of the nanosatellite and performed the whole system engineering, while the DLR Institute of Composite Structures and Adaptive Systems in Braunschweig took the responsibility for the experimental verification of the helical antenna. The Schütze Company in Dorsten performed the manufacturing of the antenna hardware and for corresponding material creep tests.

As far as electrical engineering and AIS signal processing are concerned, DLR's key partners are the Bremen University of Applied Sciences and a consulting company (Joachims). However, their contributions are not discussed in the present paper.

The maiden flight of the first AISat satellite is already planned for 2011. The satellite will be launched on a Polar Satellite Launch Vehicle from the Satish Dhawan Space Centre on the Island of Sriharikota, India.

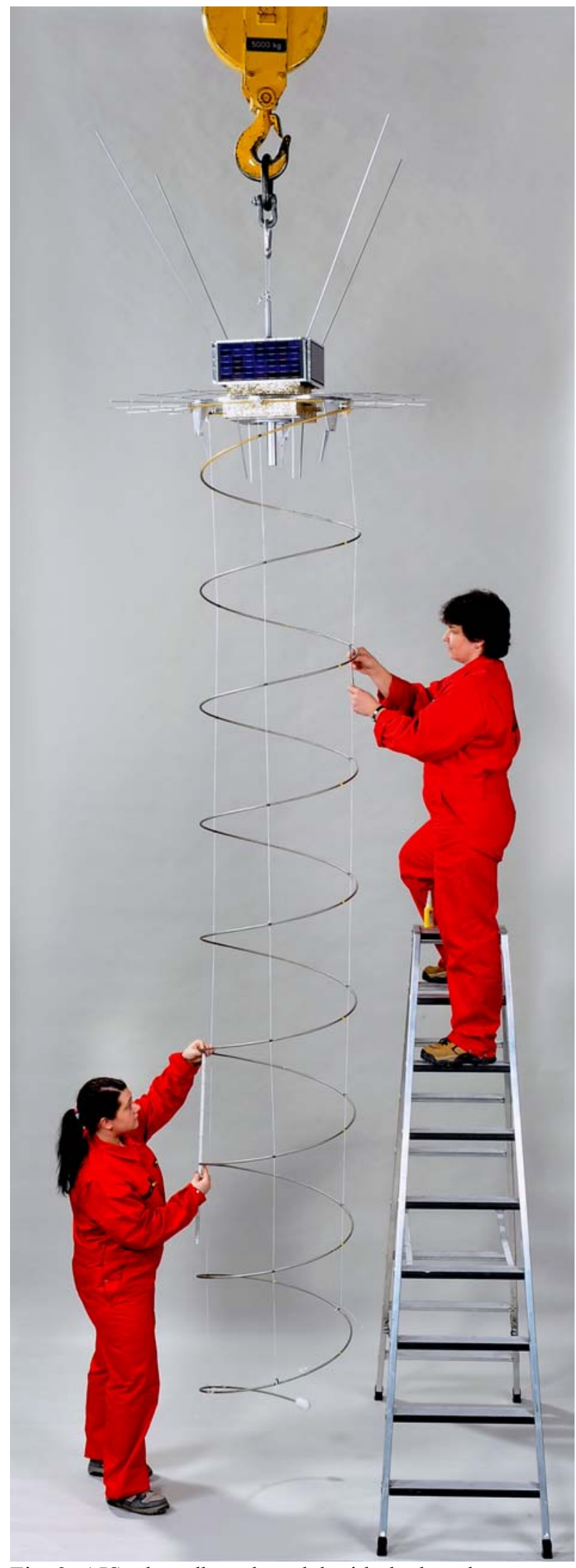

Fig. 2: AISat breadboard model with deployed antenna 


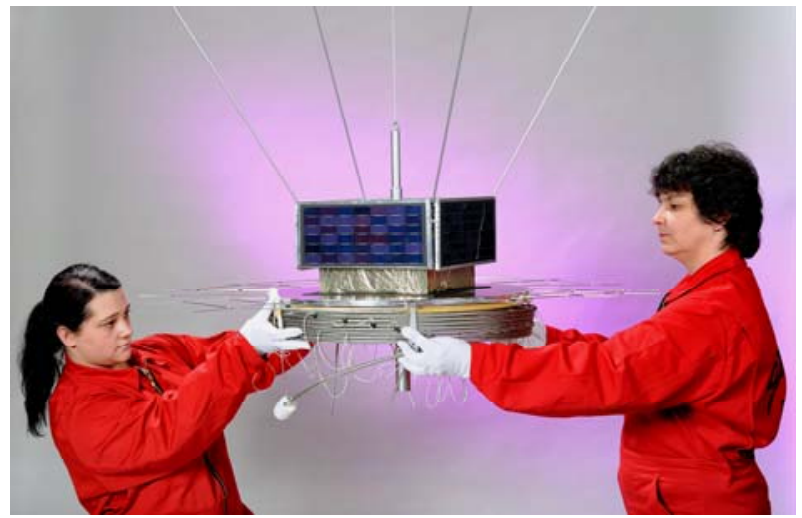

Fig. 3: AISat breadboard model with stowed antenna

\section{DESIGN AND MANUFACTURING}

The manufacturing process of the helical antenna consists actually of four consecutive processes:

\subsection{Primary Composition}

At first, the (carbon-)fiber fabric hose is pulled upon the cylindrical hard foam core, impregnated with epoxy resin, and then surrounded with a thin PE hose which serves as a means for radial shrinkage. This process is almost identical with the well-proven production process of straight carbonfiber struts ${ }^{3}$, apart from two differences: The shrinkage hose consists of PE instead of glassfibers, and there are no unidirectional fibers in longitudinal direction, because they would inevitably tend to buckle on the inner side of the windings (which cannot occur on straight struts).

\subsection{Building the Helix}

In the second step, this still very soft sandwich structure is wound upon a much larger cylindrical form which reflects the geometry of the helical antenna (see Figs. 4 and 5). This step is the most challenging task at all, because several shrinkage and creep effects have to be taken into account in advance. In longitudinal direction, the overall length of the helix must be significantly larger during manufacturing (i.e. during the winding upon the cylindrical form) than in the nominal design case (Fig. 6). In radial direction, it must be considered that any elongations and shortenings of the helix will simultaneously influence the winding radius.

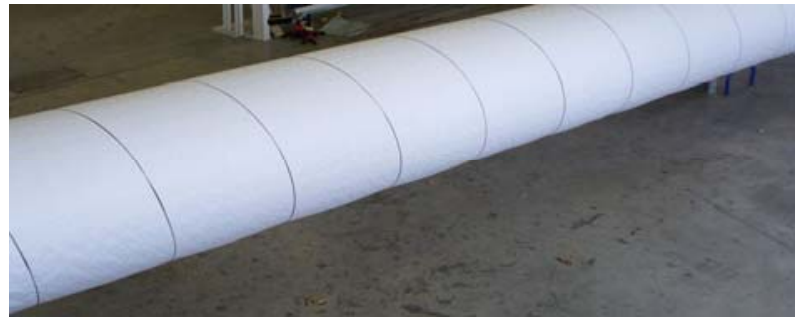

Fig. 4: Cylindrical winding form (the later helical geometry marked with a carbonfiber filament)

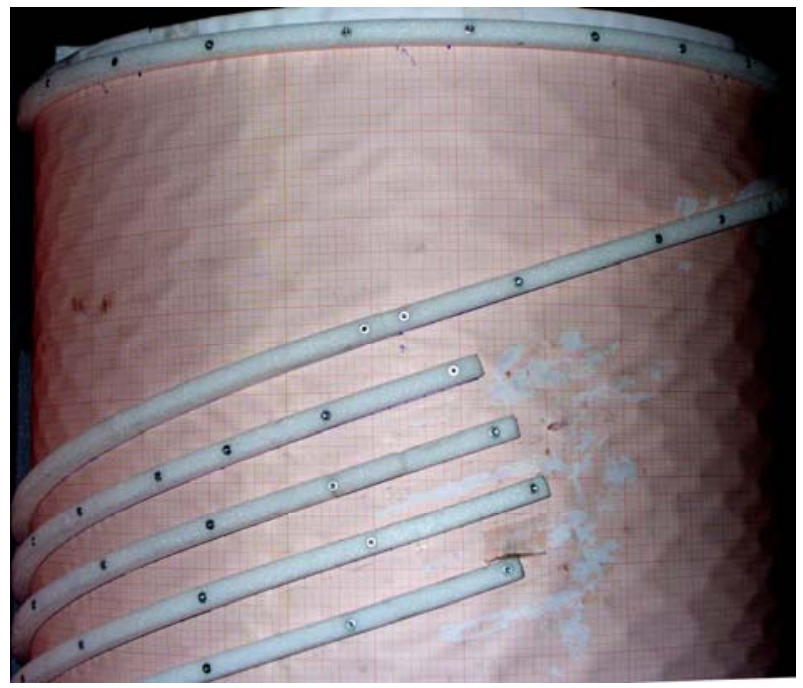

Fig. 5: Lay-up traces (foam beds) on a winding form

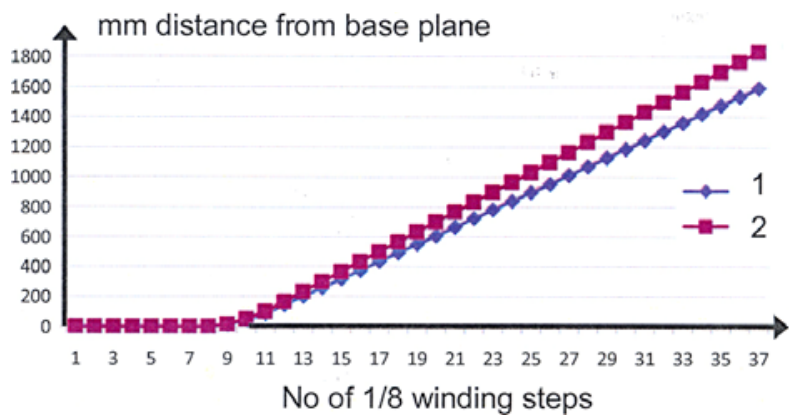

Fig. 6: Additional pitch (curve 2) must be foreseen in comparison to the nominal geometry (curve 1). The position on the cylindrical winding form is measured and fixed eight times per winding, i.e. all $45^{\circ}$

Once the desired manufacturing contour has been fixed upon the cylindrical form, the whole helix is being hardened and cured at elevated temperatures $\left(+60^{\circ} \mathrm{C}\right.$ and $+80^{\circ} \mathrm{C}$ ). But even after curing it remains subject to creep effects: Long-term stowage in the compressed configuration will significantly reduce the overall length upon sudden release, and only after longer relaxation periods the material will slowly "regenerate" (Fig. 7).

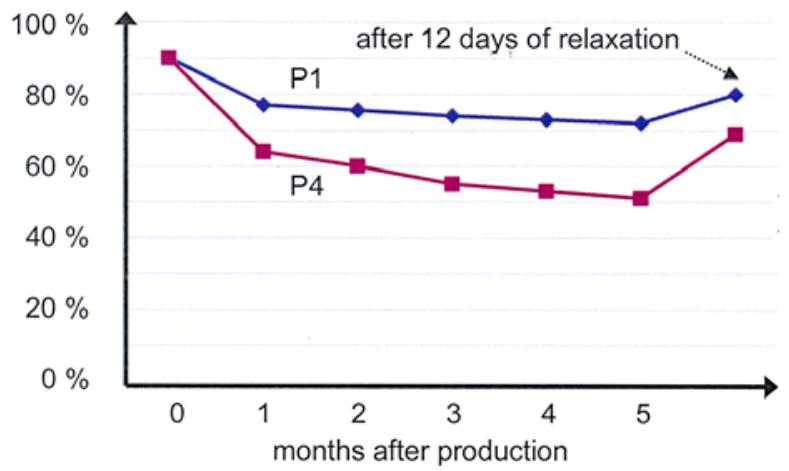

Fig. 7: Length reduction after long-term stowage in the compressed state 


\subsection{Application of the Conductive Coating}

Finally, when the cylindrical form is removed and the curing at $+80^{\circ} \mathrm{C}$ is accomplished, the ready antenna core can be covered with the metallic fabric hose. At the root of the first antenna winding, however, there should remain an electric "gap", i.e. after mounting on the reflector plate there should be no conductive connection. Instead, the metallic fabric hose will be connected to the electric circuitry on board the satellite by a suited cable.

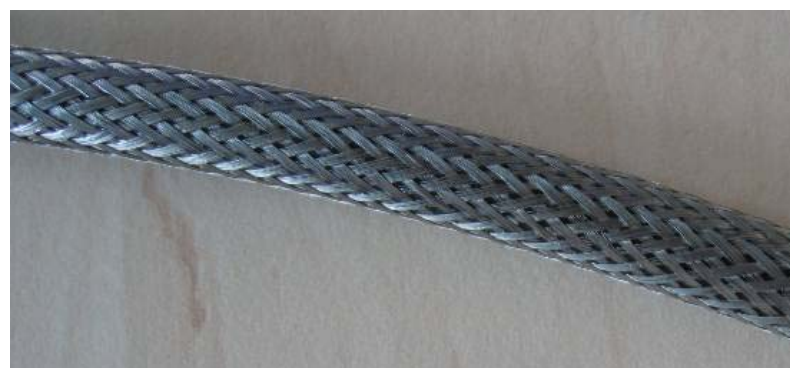

Fig. 8: Detailed view of the conductive coating. The tested antenna core diameters were 7 and $8 \mathrm{~mm}$

\subsection{Application of the Control Cords}

The creep and relaxation effects described above make it inevitable to manufacture the helices with sufficient "stiffness reserve", because it must be secured that the nominal operational dimensions are achieved after deployment in space under all circumstances. Therefore the manufacturing length will have to be significantly longer than the final nominal length and that, on the other hand, the residual spring forces after deployment will be considerable, in particular when the antenna is still new. This means that in circumferential direction three electrically isolating control cords are required (with an angular distance of $120^{\circ}$ between them) which have to counteract the residual spring force and to align the deployed antenna very accurately. They are fastened on precisely measured points on the top winding of the helix and, with their other end, on the reflector plate.

\section{TEST CONFIGURATION FOR ZERO-G}

It is obvious that a so-called "gossamer" structure as the helical antenna described above could never be satisfactorily tested under normal gravity. Apart from all other disturbing effects, the antenna would already be deflected downwards by its own weight immediately after release. On the other hand, the antenna could never be installed on AISat (or on any other satellite) without having been thoroughly tested and qualified. Therefore it became mandatory to test the release function, to monitor the self-deployment, and to verify the achievement of a well-aligned final attitude in space within a parabolic flight where up to 22 seconds of weightlessness per parabola are available.

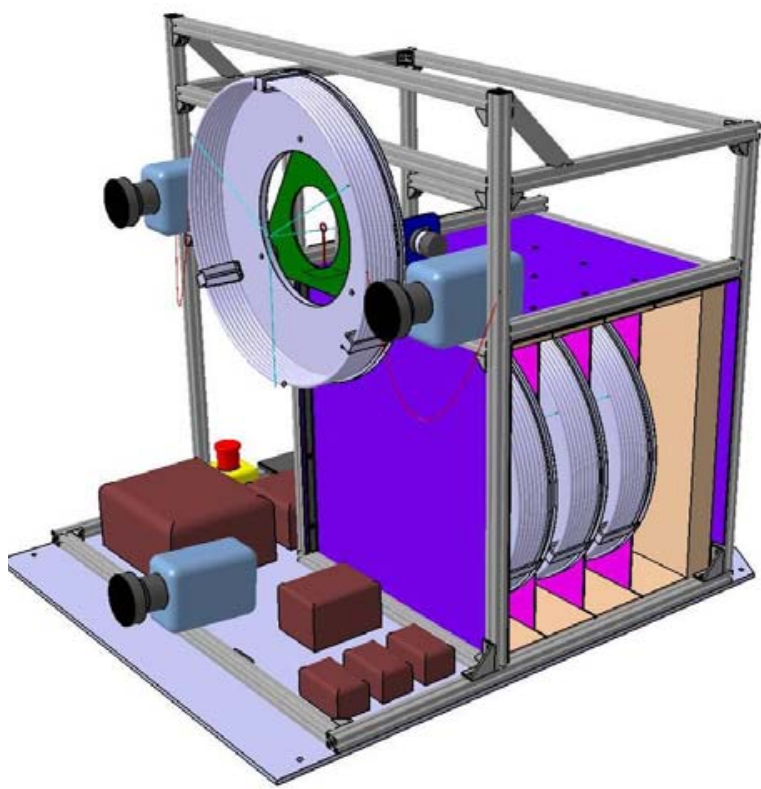

Fig. 9: Test rack for four antennas with identical geometry, but different material combinations in the helix core (carbonfibers, glassfibers, aramide fibers)

Consequently, four slightly different types of the AISat antenna were tested in the course of the $15^{\text {th }}$ DLR Parabolic Flight Campaign in Bordeaux (France) on March 9, 2010.

These antennas were stored in their stowed configuration in a magazine on the test rack. For each test series ( 5 parabolas) one of them was taken out and locked on a circular antenna ground plate (a sandwich plate) in vertical position (Fig. 9). The test rack itself was a heritage from a previous DLR test campaign ${ }^{4}$.

Once released, the antennas should safely unfold up to a total length of $\approx 4 \mathrm{~m}$, with a helix diameter of $0.57 \mathrm{~m}$. The three release mechanisms are manually triggered upon injection into the zero-g phase by cutting a circumferential string which holds their hold-down flanges down (Fig. 10). They did not need any control electronics. In space, one could use a simple cutter.
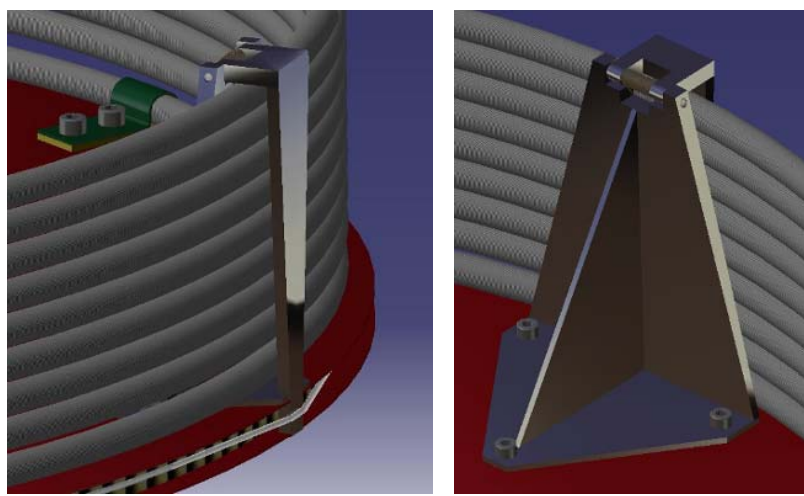

Fig. 10: Outside and inside view of one of the release mechanisms. The hinge is driven by a torsion spring 
The antennas were mounted on the triangular antenna ground plate via force transducers so that the reaction forces upon deployment could be measured.

Simultaneously, three video cameras fastened on the test rack and two additional cameras mounted on the aircraft handrail behind the test rack, respectively, $\approx 4 \mathrm{~m}$ ahead of it, monitored the unfolding process. All cameras were self-recording. They were switched on prior the first parabola and switched off after the last parabola.

In addition to the control cords discussed above there were some additional glassfiber cords for safety and retraction purposes, due to the strict safety regulations on board the aircraft ${ }^{5}$.

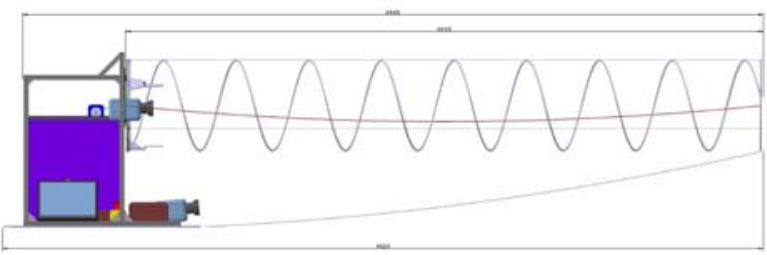

Fig. 11: Test scheme for the deployed configuration

\section{RESULTS OF THE ZERO-G TESTS}

The 31 parabolas performed during the flight were divided into 6 series of 5 parabolas each, plus one initial parabola to become familiar with the procedure. Table 1 summarizes the test plan for the AISat antenna.

\begin{tabular}{cccc}
\hline $\begin{array}{c}\text { Parabola } \\
\text { Sequence }\end{array}$ & $\begin{array}{c}\text { Test } \\
\text { Object }\end{array}$ & Composition & $\begin{array}{c}\text { String } \\
\text { Diameter }\end{array}$ \\
\hline 1 & Antenna 1 & CFRP + GFRP & $9.5 \mathrm{~mm}$ \\
2 & Antenna 2 & Aramide FRP & $9.5 \mathrm{~mm}$ \\
3 & Antenna 3 & CFRP + GFRP & $8.5 \mathrm{~mm}$ \\
4 & Antenna 4 & Aramide FRP & $8.5 \mathrm{~mm}$ \\
5 & Repetition of most promising sequence \\
6 & as 5, and photographic documentation \\
\hline
\end{tabular}

Table 1: Test plan for the AISat antenna

It could be successfully verified that within the 22 seconds of zero-g conditions in each parabola the helical antenna structure can be completely deployed to its full length. Other than in the simple idealized simulation depicted in Fig. 12, however, the presence of the control cords leads to strong vibrations induced by the rebounds which occur when the cords are tightened.

The numerical simulation of these vibrations (in 3D), and a deepened evaluation of the parabolic flight records are still ongoing. Nevertheless it can be stated that in each test the amplitude of all these vibrations steadily decreased, although the antenna as a whole was not yet calm when the 22 seconds of weightlessness were over. But on the real mission sufficient time will be available.

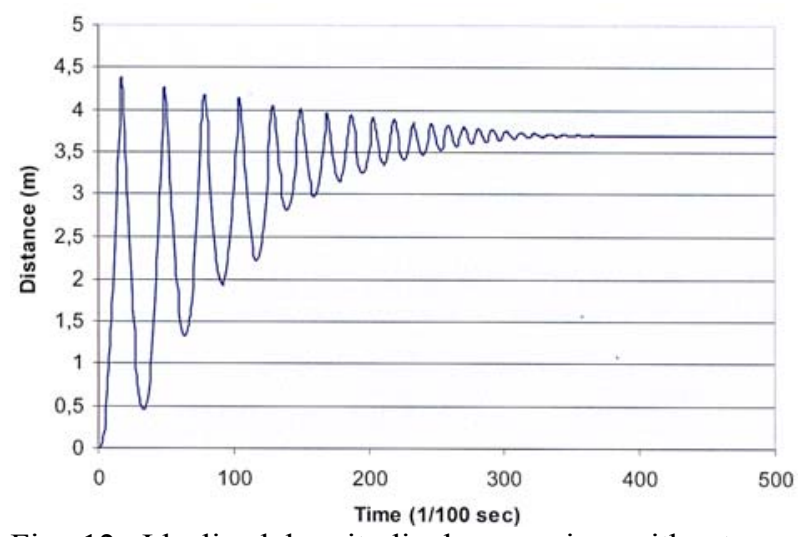

Fig. 12: Idealized longitudinal expansion without any control cords: in reality, however, the peaks are cut when the cords reach their final length, and the rebounds induce lateral and torsional vibrations

As far as the directionality of the forward motion is concerned, it was observed that friction of the antenna windings on the flanges of the release mechanisms has a strong effect on the initial direction into which the unfolding antenna moves. Here a design improvement is mandatory (and has already been realized). If the initial expansion is strongly misaligned then the points in time when the three control cords reach their final length will strongly differ, so that the antenna rebounds in an asynchronous manner, and the vibrations become worse.

Finally it became obvious during the test campaign that material stiffness is advantageous, so that the final AISat antenna (the flight unit) will certainly get a carbonfiber-dominated core (CFRP).

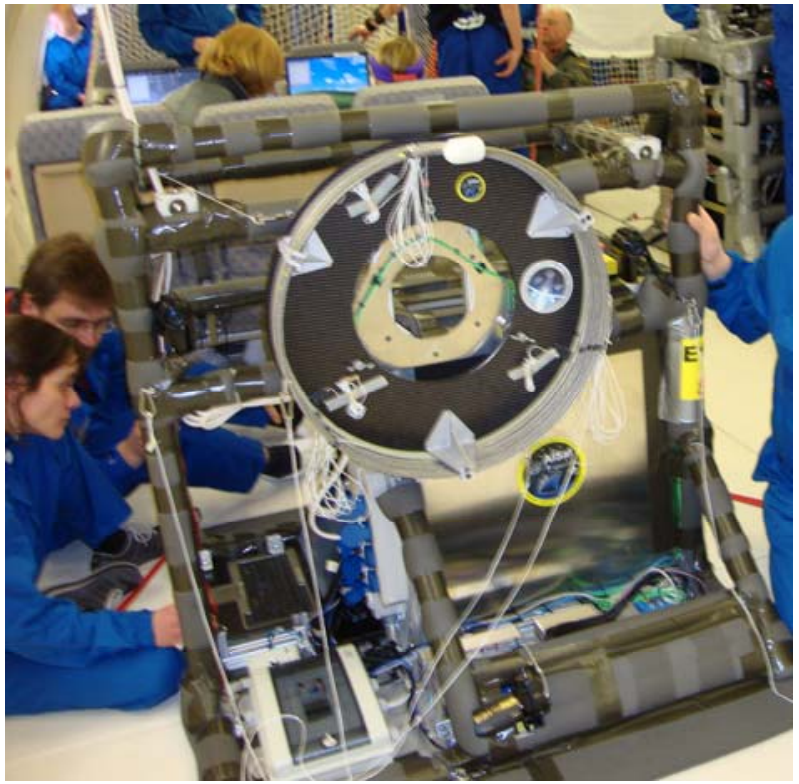

Fig. 13: Test rack with stowed antenna. The white loops hanging down from the antenna are the control cords 

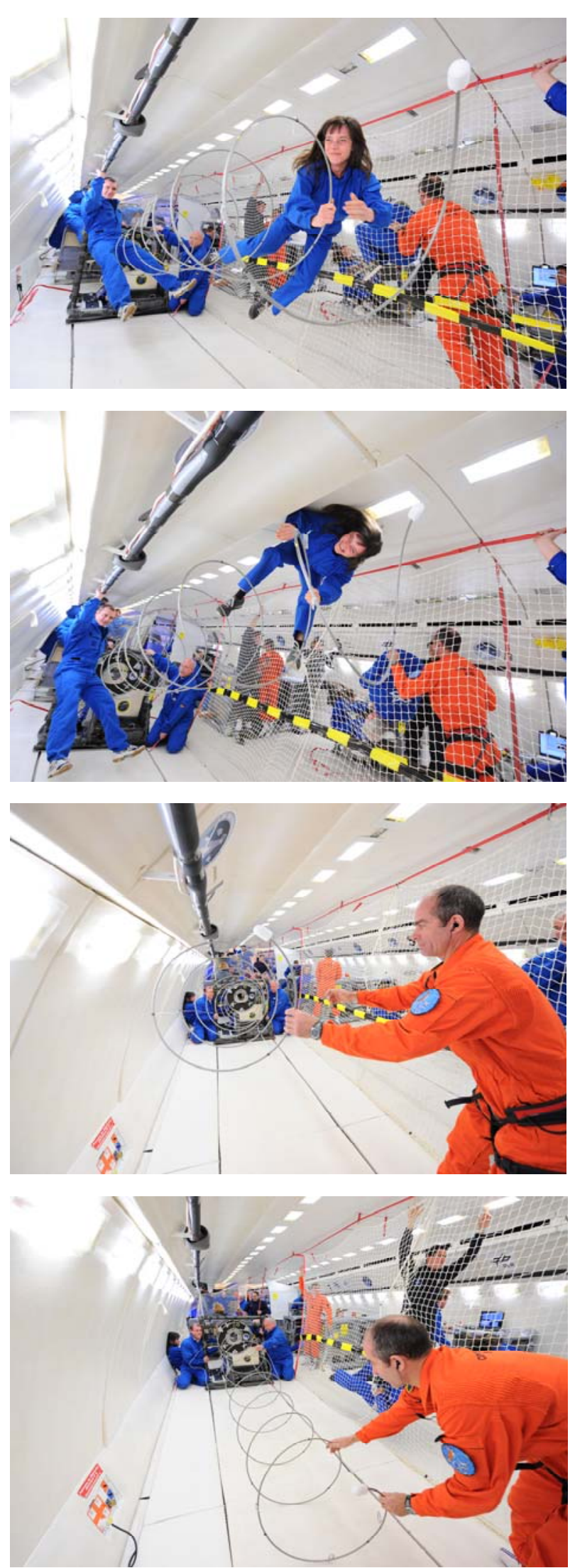

Fig. 14: Grasping the deployed antenna (4 scenarios)

\section{CONCLUSIONS}

Although the complete evaluation of the parabolic flight tests has not yet been finalized (September 2010), the most decisive conclusions and preliminary results are already at hand:

- The concept of a helical antenna which can be stowed and then, upon release, expand like a compression spring, is feasible.

- With a stiffness reserve that is large enough to compensate losses induced by material creep and relaxation, and with suited control cords which limit the expansion, the helices will achieve a stable final length which can be adjusted in accordance with the electromagnetic requirements.

- The direction into which the antenna moves forward immediately after release depends strongly on the uniformity of its interaction with the release mechanisms. High-quality release mechanisms with little friction will help to make the expansion as straight as possible.

- The vibrations induced by the expansion and, in particular, by rebounds of the antenna tip when the control cords are tightened, decrease obviously; although there was not sufficient time during the zero-g phases to make the antenna calm.

- The overall performance of carbonfiber-based antenna cores is superior to competing types. Consequently the AISat flight model will be equipped with such an antenna.

\section{REFERENCES}

1 King H.E., Wong J.L, Newman, E.H, Helical Antennas, in: Volakis J.L. (Ed.), Antenna Engineering Handbook, McGraw-Hill, New York 2007

2 Balanis C.A., Modern Antenna Handbook, Wiley, Hoboken NJ 2008

3 Schütze R., Lightweight Structures based on CFRP Sandwich Struts and CFRP Connections. Proceed. Internat. Symp. on Advanced Materials for Lightweight Structures, Noordwijk, March 1994 (ESA-WPP-070)

4 Block J., Straubel M., Wiedemann M., Ultralight Deployable Booms for Solar Sails and other Large Gossamer Structures in Space, IAC-09-C2.2.2 and Acta Astronautica AA-3954

5 NOVESPACE A300 Zero-G Rules and Guidelines, RG-2009-1, Bordeaux 2009 